\title{
Temephos Removal From Water Samples by Silver Modified Zero-Valent Iron Nanoparticles
}

\author{
Roohollah Shiralipour ${ }^{1, *}$; Behrooz Zargar $^{1}$; Hooshang Parham ${ }^{1}$ \\ ${ }^{1}$ Chemistry Department, College of Science, Shahid Chamran University, Ahvaz, IR Iran \\ ${ }^{*}$ Corresponding author: Roohollah Shiralipour, Chemistry Department, College of Science, Shahid Chamran University, Ahvaz, IR Iran. Tel: +98-6133360018, Fax: +98-6133337009, \\ E-mail: shiralipour-r@ajums.ac.ir
}

Received: October 31, 2014; Revised: December 5, 2014; Accepted: December 27, 2014

\begin{abstract}
Background: Temephos is an organophosphate pesticide used as larvicide in the environment. Although not extremely hazardous, it can be risky for human health in the moderate concentrations.

Objectives: This study investigated the quantitative removal efficiency of temephos, an organophosphate pesticide, from contaminated water by silver-modified ZVINPs. In addition, the operational parameters affected on removal process were optimized.

Materials and Methods: In the current study, three water samples from different parts of Iran such as Ahvaz tap water, the Karoon River passing through Khoramshahr city, and the Caspian Sea were collected. A new method for effective removal of temephos from the sample solutions by silver modified zero-valent iron nanoparticles as an efficient adsorbent was introduced.

Results: For a typical solution in which temephos was removed about $21 \%$ by iron zero-valent nanoparticles, modification by silver improved removal method was up to about $99 \%$. The required time for the complete removal of temephos was about eight minutes. Variation of $\mathbf{p H}$ and concentration of $\mathrm{KNO}_{3}$ as an electrolyte was considerably ineffective on the efficient temephos removal. Adsorption studies of the method were followed by Langmuir isotherm. Maximum temephos adsorption amount was 12.65 $\mathrm{mg} / \mathrm{g}$ under optimal conditions. The proposed method was simple, fast and safe to treat temephos polluted waters. Preparation of the adsorbent was easy and removal time was short.

Conclusions: Briefly, the current study represents a novel method to eliminate temephos as an organophosphate compound from water samples with modified zero-valent iron nanoparticles.
\end{abstract}

Keywords: Temephos; Removal; ZVINPs; Silver

\section{Background}

Insects transfer a wide range of pathogen microorganisms between humans and animals. Insecticides are employed to control the contagion of such diseases. Organophosphate insecticides are extensively used worldwide. Generally, the inhibition mechanism of organophosphate pesticides (OP) is inactivation of cholinesterase in the insect as well as mammal (1).

The organophosphates are a group of pesticides that affect the nervous system functions, and the Environmental Protection Agency (EPA) assessed the risks of these pesticides. They are among the EPA's highest priority review under the Food Quality Protection Act (FQPA). Organophosphates are strongly bound to cholinesterase molecules, which inactivates them. True cholinesterase (acetyl cholinesterase) and plasma cholinesterase (pseudo cholinesterase) play vital roles in human body. These two cholinesterases are responsible for neurochemical transmissions. Temephos can cause cholinesterase inhibition in humans; that is, it can over stimulate the nervous system causing nausea, dizziness, confusion, and at very high exposures, such as accidents or major spills, respiratory paralysis and death (2).
Development of industrial processes in the developing, and high birth rate and overpopulation countries cause using high rate of pesticide and more environmental pollution. Temephos is one of the few organophosphates registered by EPA, widely used to control mosquito larvae, and is the only organophosphate with appreciable larvicidal property. It is an important resistance management tool for mosquito abatement programs. Temephos usage is approximately $25^{\prime} 000$ to 40 '000 pounds per year. This pesticide is used to control mosquito, midge, gnat, punkie, and sand fly larvae in non-potable water (stagnant, saline, brackish and temporary water bodies), highly polluted water, including humid areas, woodland pools, shallow ponds, edges of lakes, swamps, marshes, tidal waters, intertidal zones, catch basins and tire piles (2).

Although temephos is one of the low hazardous organophosphate pesticides for mammals ' health, it can be harmful in higher concentrations. According to the World Health Organization (WHO) standards, the maximum permitted level proposed for temephos in drinking water is $1 \mathrm{mg} / \mathrm{L}(3)$.

Copyright (c) 2015, Ahvaz Jundishapur University of Medical Sciences. This is an open-access article distributed under the terms of the Creative Commons Attribution-NonCommercial 4.0 International License (http://creativecommons.org/licenses/by-nc/4.0/) which permits copy and redistribute the material just in noncommercial usages, provided the original work is properly cited. 
In the environmental water, temephos is used with a surfactant or as granulates due to its trace solubility in water. The current study used a new method to investigate the removal efficiency of temephos by dissolving temephos in an aqueous solution with n-Octyl- $\beta$-DGlucopyranoside as a surfactant.

Zero-valent iron nanoparticles (ZVINPs) are widely used to inactivate microbes $(4,5)$, eliminate dyes (6-12), and toxins such as heavy metals (13-17) and pesticides (18, 19). According to the authors best knowledge, no report is found on the removal of organophosphate pesticides using ZVINPs, exclusively. Due to low removal efficiency of unmodified ZVINPs, modification of these particles is necessary to increase the efficiency of adsorbent. To improve the removal efficiency of ZVINPs particles some metal elements and/or organic compounds are used (2024). Silver is one of the metal elements that can be used to develop the removal characteristics of ZVINPs adsorbent $(25,26)$. In ion or zero-valent form, silver naturally has antibacterial trait (27-36) and furthermore is a nice choice to remove thiol containing compounds due to high reactivity between silver and sulfur in aqueous solutions. Temephos is one of the organophosphate pesticides that contain three sulfur atoms in its chemical structure Figure 1.

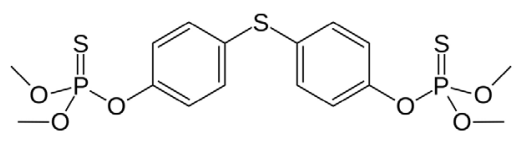

Figure 1. Chemical Structure of Temephos

\section{Objectives}

The current research mainly aimed to investigate a modified SPE method to remove temephos, as an organoposphate pesticide, from aqueous solutions with silver-modified ZVINPs. Afterwards, the effect of some parameters such as silver amount as a modifier of ZVINPs particles, $\mathrm{pH}$, contact time, adsorbent amount, electrolyte, interfering species, and solution volume on temephos removal efficiency was determined. Finally, the applicability of the proposed method was studied on real water samples spiked with temephos at a definite value.

\section{Materials and Methods}

\subsection{Instrumental}

A Knauer HPLC system equipped with a Knauer Smartline pump 5000, a Smartline UV detector 2500 and a C18 analytical column $(250 \times 3 \mathrm{~mm}, 5 \mu \mathrm{m}$ dimensions, Macherey-Nagel, Duren, Germany) were used to determine temephos in water sample solutions.

An infrared spectrum was obtained, using a Fourier Transform-Infrared Spectrometer (FT-IR, Perkin Elmer, spectrum 100), to identify the functional groups and chemical bonding of the adsorbent and adsorbed materials on the adsorbent. Transmission electron microscopy (LEO, 906E, $120 \mathrm{kV}$, Germany) was performed to measure the size and shape of particles. Structural analysis of the silver modified zero-valent iron nanoparticles (AgZVINPs) was carried out using an X-ray diffractometer (XRD, Brucker D8 Discover, Germany). FRITSCH Laser particle sizer ANALYSTTE 22 nanotech plus (Germany) was used to measure the size distribution of Ag-ZVINPs. An IKA works KS 130 orbital shaker (IKA Works Basic Model), a Jenway hotplate model 1000 (UK), a Jenway pH meter model $3510(\mathrm{UK})$, and a magnet $(1.2 \mathrm{~T}, 10 \times 5 \times 2 \mathrm{~cm})$ were used during the experiments.

\subsection{Reagents}

All the solutions were prepared by double distilled deionized water with electrical conductivity below $1.5 \mu \mathrm{S} / \mathrm{cm}$.

Pure temephos powder (Fluka) was used to prepare test solutions. Temephos stock solution $(1000 \mu \mathrm{g} / \mathrm{mL})$ was prepared in HPLC grade acetonitrile. $\mathrm{FeCl}_{3}(96 \% \mathrm{w} / \mathrm{w}), \mathrm{NaBH}_{4}$, $0.1 \mathrm{M} \mathrm{AgNO}_{3}$ Titrisol $®$, n-Octyl- $\beta$-D-Glucopyranoside, HPLC grade water, and acetonitrile were purchased from Merck (Darmstadt, Germany).

\subsection{Preparation of Ag Modified Zero- Valent Iron Nanoparticles}

ZVINPs particles were synthesized by reduction of ferric chloride with sodium borohydride under atmosphere. For synthesis of $100 \mathrm{mg}$ ZVINPs, $1.8 \mathrm{~mL}$ of $1 \mathrm{M} \mathrm{Fe}^{3+}$ solution was added to $200 \mathrm{~mL}$ water and $10 \mathrm{~mL} \mathrm{NaBH}_{4}(1 \mathrm{M})$ was slowly added in one minute with mixing the solution by a magnetic stirrer at $600 \mathrm{rpm}$. Reduction of $\mathrm{Fe}^{3+}$ was done according to the following reaction:

$4 \mathrm{Fe}^{3+}(\mathrm{aq})+3 \mathrm{BH}_{4}{ }^{-}{ }_{(\mathrm{aq})}+9 \mathrm{H}_{2} \mathrm{O} \rightarrow 4 \mathrm{Fe}^{0}+3 \mathrm{H}_{2} \mathrm{BO}_{3}{ }^{-}{ }_{(\mathrm{aq})}+$ $12 \mathrm{H}^{+}(\mathrm{aq})+6 \mathrm{H}_{2(\mathrm{~g})}$

The synthesized ZVINPs were settled at the bottom of a beaker using a strong magnet and washed with distilled water a few times until the $\mathrm{pH}$ of washing solution reached seven. Silver was selected as the best candidate to improve the temephos adsorption property of ZVINPs due to the high tendency of silver to sulfur and phosphate groups $(37,38)$. Two different methods were carried out to modify ZVINPs. In the first procedure, both the $\mathrm{Fe}^{3+}$ ions and modifier (silver ion, $\mathrm{Ag}^{+}$) were initially mixed and then reducing agent $\left(\mathrm{NaBH}_{4}\right)$ was added to the mixed solution to form zero-valent particles simultaneously ( $\alpha$-type). In the second method, a two-step reduction process was carried out. In the first step, the ZVINPs particles were prepared according to the described method represented above and then in the second step, the modifier (silver ion) was added to the solution and reduction of $\mathrm{Ag}^{+}$ions was performed by $\mathrm{NaBH}_{4}$ solution ( $\beta$-type). In order to synthesize $\beta$-type adsorbent (Ag-ZVINPs) with ZVINPs, $2 \mathrm{~mL} \mathrm{AgNO}_{3}(0.1 \mathrm{M}$ ) was added drop wise to a 200 $\mathrm{mL}$ solution containing ZVINPs, and then $2 \mathrm{~mL}$ of $\mathrm{NaBH}_{4}$ 
solution ( $1 \mathrm{M})$ was slowly added to the medium. The solution was stirred for at least five minutes and Ag-ZVINPs were settled using a permanent magnet. The remaining solution over the nanoparticles was decanted and AgZVINPs were washed with water followed by ethanol and water sequentially up to achieving $\mathrm{pH} 7$ for the washing solution. Figure 2 shows TEM image and graph of size distribution of the synthesized Ag-ZVINPs.

\subsection{Removal Procedure}

In the current investigation, a batch process was used to eliminate temephos insecticide from water solution. For the removal procedure, $80 \mathrm{mg}$ of Ag-ZVINPs was used to adsorb $10 \mu \mathrm{g} / \mathrm{mL}$ temephos in $50 \mathrm{~mL}$ 0.05\% n-Octyl- $\beta$-DGlucopyranoside solution at room temperature and uncontrolled $\mathrm{pH}$ conditions. After mixing for eight minutes, Ag-ZVINPs were separated by a magnet from the test solution. Determination of temephos in solutions before and after removal process was performed by a HPLC-UV system.

\subsection{Analysis Procedure}

The RP-HPLC analyses were performed on a Knauer system with a 2500 UV-Vis detector. A C18 analytical column of $250 \times 3 \mathrm{~mm}, 5 \mu \mathrm{m}$ dimensions from Macherey-Nagel (Duren, Germany) was equipped with a guard column of the same material, and held at $30^{\circ} \mathrm{C}$ by a column oven. The mobile phase was pure acetonitrile (AN) solvent (100\%). All solutions were filtered through a $0.45 \mu \mathrm{m}$ cellulose nitrate membrane (Sartorius, UK) before injection and a $20 \mu \mathrm{L}$ injection loop was used throughout. The optimum flow rate of mobile phase was fixed at $1.0 \mathrm{~mL} /$ min. Temephos molecule has two absorption peaks in UV region (203 and $254 \mathrm{~nm}$ ) according to UV-Vis spectra of temephos in the acetonitrile solution. The maximum intensity was achieved at $203 \mathrm{~nm}$. Validated linear dynamic range of the temephos concentration using HPLC method was 0.05-20.0 $\mu \mathrm{g} / \mathrm{mL}$.

\subsection{Sampling}

Water samples used in the current study were collected from three main sources: (1) tap water from Ahvaz City (Khuzestan, Iran), (2) the Karoon River passing through Khoramshahr City (Khuzestan, Iran) and (3) the Caspian Sea (Iran).

Fifty milliliters of all three samples were spiked by 0.25 $\mathrm{mL}$-Octyl- $\beta$-D-Glucopyranoside (10\%) and $0.5 \mathrm{~mL}$ temephos $(1000 \mathrm{mg} / \mathrm{L})$ to reach the total volume of $10 \mathrm{mg} / \mathrm{L}$ temephos solutions. Removal efficiency of the method was studied by determination of temephos before and after adsorption process.

\section{Results}

\subsection{Characterization of the Ag-ZVINPs}

FTIR spectrums Figure 3 show the characteristics of temephos peaks (A), adsorbent Ag-ZVINPs (B), and temephos on Ag-ZVINPs (C). The rocking vibrations for P-O-Me were found at $1190-1170 \mathrm{~cm}^{-1}$ in Figure 3 a for temephos, and Figure $3 \mathrm{c}$ for temephos-Ag-ZVINPs. The mentioned peaks are typically very weak due to the aggregation of P-O-Me groups within the monolayer. The presence of out-ofphase P-O-C stretching $\left(920-1088 \mathrm{~cm}^{-1}\right)$ vibration in Figure $3 \mathrm{c}$ shows the adsorption of temephos on the adsorbent. The absorption bands at 725-845 $\mathrm{cm}^{-1}$ for both temephos and temephos-Ag-ZVINPs are usually attributed to the in phase P-O-C stretching. The peak at $1400-1500 \mathrm{~cm}^{-1}$ is due to $\mathrm{P}=\mathrm{S}$ stretching in Figure $3 \mathrm{a}$, and shows a small shift (about $20 \mathrm{~cm}^{-1}$ ) to lower wave numbers due to the chemical interaction between $\mathrm{Ag}$ (from $\mathrm{Ag}$-Fe adsorbent) and $\mathrm{S}$ atom of temephos in Figure $3 \mathrm{c}(37,38)$.
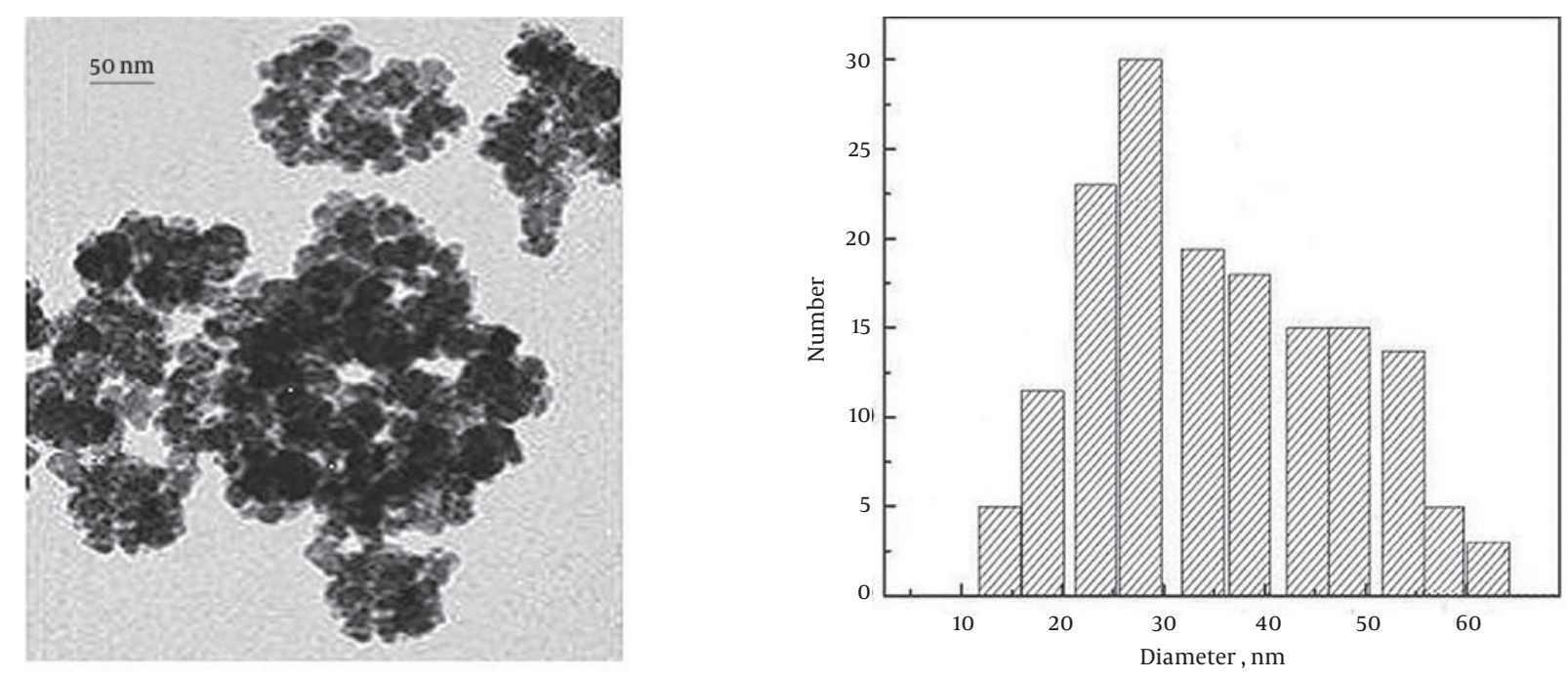

Figure 2. TEM Image and Graph of Size Distribution of the Synthesized Ag-ZVINPs 


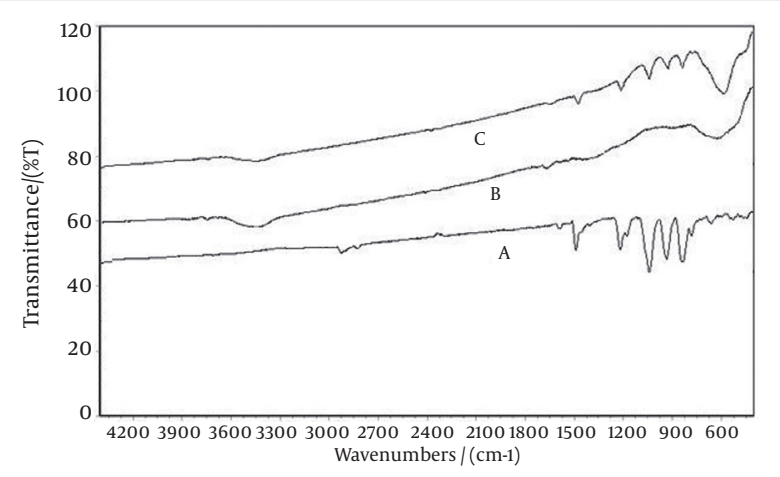

Figure 3. FT-IR Spectrum of Temephos (A), Ag-ZVINPs (B) and TemephosAg-ZVINPs (C)

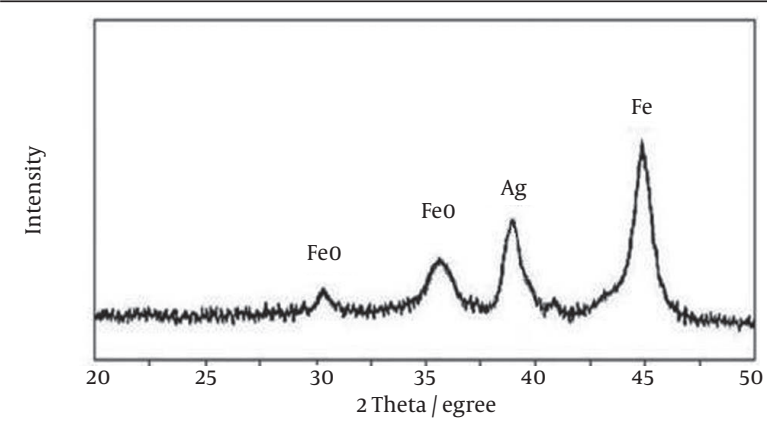

Figure 4. X-ray Diffraction Pattern of Ag-ZVINPs

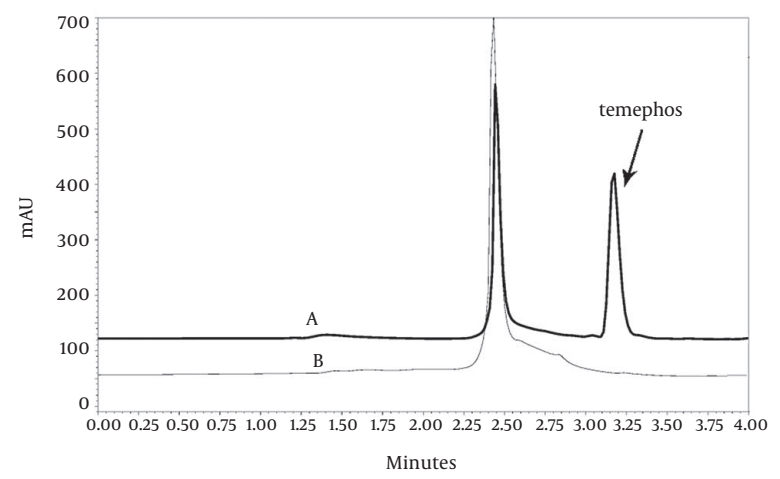

Figure 5. Chromatograms of water samples containing $10 \mathrm{mg} / \mathrm{L}$ of temephos using C18 analytical column of $250 \mathrm{~mm} \times 3 \mathrm{~mm}, 5 \mu \mathrm{m}$ dimensions (A) before and (B) after adsorption by Ag-ZVINPs at $25^{\circ} \mathrm{C}$

The X-ray diffraction (XRD) pattern for synthesized AgZVINPs in Figure 4 shows the presence of $\mathrm{Ag}^{0}$ and $\mathrm{Fe}^{0}$ in the adsorbent. The diffraction peak at $2 \theta=38.28^{\circ}$ corresponds to the standard face-centered-cubic (fcc) phase of $\mathrm{Ag}$. It can be concluded that the peak at $2 \theta=44.34^{\circ}$ in Figure 4 comes from the body-centered-cubic (bcc) phase of $\mathrm{Fe}(\alpha-\mathrm{Fe})$ as well. The intensity of diffraction peaks of $\mathrm{Ag}$ is relatively weaker than that of Fe because of smaller concentration of Ag compared to Fe (Ag: Fe is about 20:100) in the adsorbent. It must be mentioned that the diffraction peak at $2 \theta=44.34^{\circ}$ for $\mathrm{Ag}$ is covered by the peak for Fe at $2 \theta=44.34^{\circ}$. Some FeO (due to oxidation of Fe) diffraction peak of iron oxides can be observed.

\subsection{Effect of ZVINPs Modification on Temephos Re- moval}

Removal ability of ZVINPs was investigated by addition of $100 \mathrm{mg}$ of the nanoparticles to a $50 \mathrm{~mL}$ solution of temephos $(50 \mu \mathrm{g} / \mathrm{mL})$ adjusted in $\mathrm{pH} 7$ and the mixture was stirred for eight minutes at $250 \mathrm{rpm}$. Since the removal was only about $21 \%$, it was necessary to modify the magnetic ZVINPs for more efficient removal. In order to increase the potential ability of ZVINPs as an efficient adsorbent to remove temephos, silver ion was selected and added to the solution in order to modify the $\mathrm{Fe}^{0}$ nanoparticles. Silver has high affinity for binding to sulfur/phosphate containing compounds $(37,38)$.

Obtained results showed that $\beta$-type Ag-ZVINPs act as better adsorbent for removal of temephos ( > 99\%) compared to $\alpha$-type (80\%) and also non-modified ZVINPs (21\%). Figure 5 shows the chromatograms of a water sample containing $10 \mathrm{mg} / \mathrm{L}$ of temephos before and after adsorption by Ag-ZVINPs. As it can be observed in chromatogram $5 \mathrm{~B}$, the peak for temephos is eliminated (>99\%) due to the adsorption of analyte on the surface of Ag-ZVINPs.

\subsection{Effect of Silver Amount as a Modifier of ZVINPS Particles}

The amount of Ag to modify ZVINPs and its effect on temephos removal from $50 \mathrm{~mL}$ solutions $(10 \mathrm{mg} / \mathrm{L})$ at previously optimized conditions ( $\mathrm{pH}=7$, contact time $=10$ minutes, $25^{\circ} \mathrm{C}$ ) was investigated. According to the results Figure $6 ;(22 \mathrm{mg})$ of silver in the presence of 100 mg of ZVINPs can produce an adsorbent (Ag-ZVINPs) with acceptable removal efficiency (more than 99\%) of temephos. Higher amounts of $\mathrm{Ag}^{+}$do not enhance removal efficiencies for solutions with such dilutions. It must be mentioned that to remove temephos from more concentrated water samples $(20 \mathrm{mg} / \mathrm{L})$ using modified ZVINPs (Ag-ZVINPs), and higher contents of $\mathrm{Ag}^{+}$act more efficiently. Figure 7 shows the comparison of removal efficiencies of the two types of Ag-ZVINPs prepared by two different percentages of silver compared to the fixed amounts of ZVINPs (100 mg). One type contains about 13\% and the other about $23 \%\left(\mathrm{w} / \mathrm{w}\right.$ ) of $\mathrm{Ag}^{+}$compared to the total weight of the Ag-ZVINPs.

\subsection{Effect of $p H$}

The effect of $\mathrm{pH}$ on the adsorption of temephos $(50 \mathrm{~mL}$, $10 \mathrm{mg} / \mathrm{L}$ ) by $100 \mathrm{mg}$ Ag-ZVINPs at $25^{\circ} \mathrm{C}$ for 10 minutes contact time (stirring at $250 \mathrm{rpm}$ ) is shown in Figure 8. As it is observed, $\mathrm{pH}$ variation in a wide range from 3.0 to 12.0 has no effect on the removal efficiency of temephos from polluted water samples. It seems that $\mathrm{pH}$ variation cannot affect the high tendency of Ag-ZVINPs to adsorb temephos (>99\%) from aqueous medium, while non-modified ZVINPs show low tendency for temephos removal (about $21 \%$ ). In the rest of investigation, $\mathrm{pH} 7$ was adjusted as optimum solution $\mathrm{pH}$ prior to analysis. 


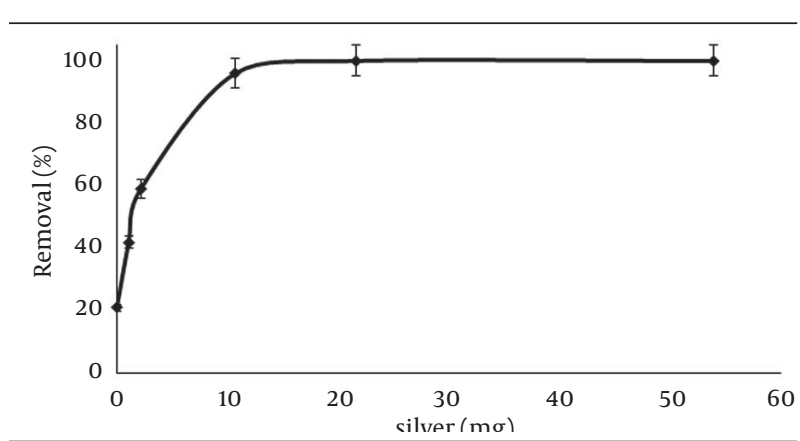

Figure 6. The Effect of $\mathrm{Ag}^{+}$ion Concentration on Modification of ZVINPs (100 mg) for Quantitative Removal of Temephos From 50mL Solutions (10 mg/L)

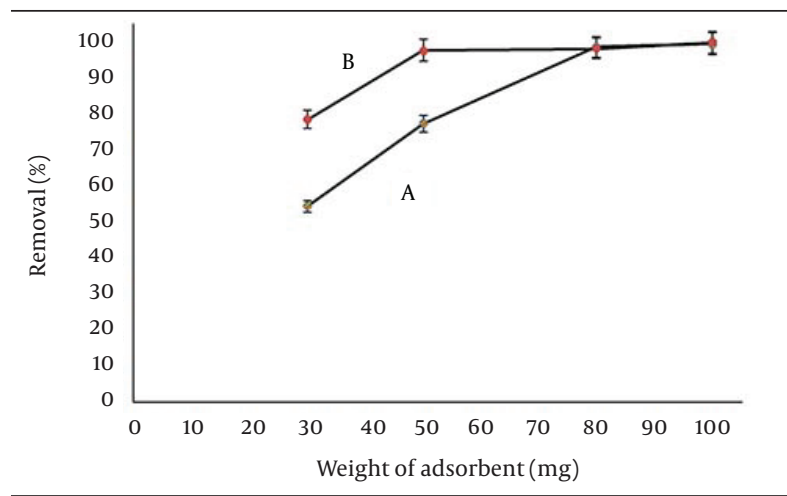

Figure 7. Comparison of Removal Percentages of the Two Types of AgZVINPs Prepared by two Different Percentages of Silver Ions in the Presence of Fixed Amount of ZVINPs. (A) Ag-ZVINPs adsorbent contains about $13 \%(\mathrm{~W} / \mathrm{W})$ of $\mathrm{Ag}^{\mathrm{O}}$ and (B) adsorbent contains about $23 \%(\mathrm{w} / \mathrm{w})$ of $\mathrm{Ag}^{\mathrm{O}}$.

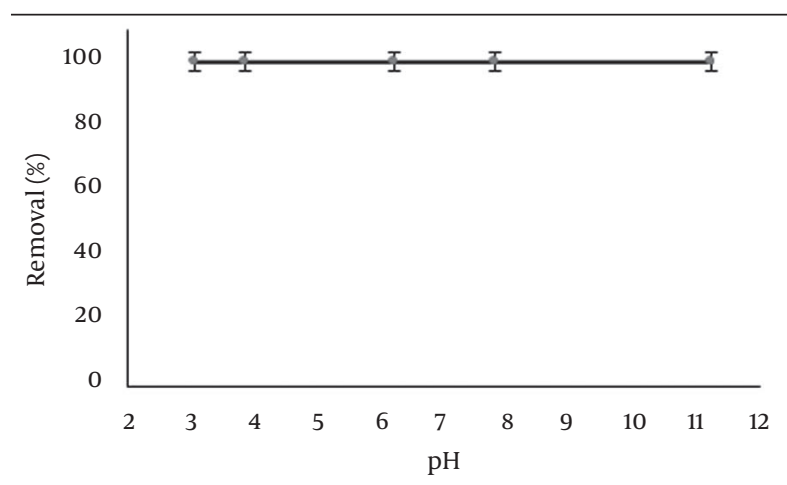

Figure 8. The Effect of Solution $\mathrm{pH}$ on the Quantitative Removal of Temephos Using Ag-ZVINPs at $25^{\circ} \mathrm{C}$

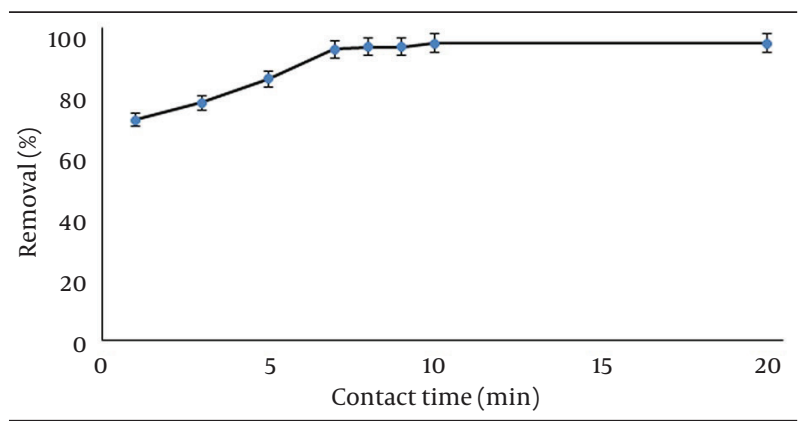

Figure 9. The Effect of Contact Time Between Ag-ZVINPs and Temephos Solutions for Quantitative Removal of the Analyte (10 mg/L) at Optimized pHCondition

\subsection{Effect of Contact Time}

To investigate the effect of contact time on the removal process, time duration from one up to 20 minutes was tested at $25^{\circ} \mathrm{C}$ and mixing rate of $250 \mathrm{rpm}$ on $50 \mathrm{~mL}$ solution of $10 \mathrm{mg} / \mathrm{L}$ temephos at $\mathrm{pH} 7$ using $100 \mathrm{mg}$ of $\mathrm{Ag}$ ZVINPs as adsorbent. Removal efficiencies above 95\% were achieved at eight minutes contact time, but 10 minutes was selected as the time for approximately complete removal of temephos under the above mentioned condition. Results are shown in Figure 9.

\subsection{Effect of the Adsorbent Amount}

In order to obtain optimum amount of the modified AgZVINPs adsorbent for quantitative removal of temephos from $50 \mathrm{~mL}$ solution (10 $\mathrm{mg} / \mathrm{L})$, different quantities of prepared Ag-ZVINPs (from 30 to $100 \mathrm{mg}$ ) were tested to remove temephos from water samples. Maximum removal achieved when $90 \mathrm{mg}$ of Ag-ZVINPs particles was used. The optimum amount of adsorbent (Ag-ZVINPs) used in the other experiments was selected as $100 \mathrm{mg}$

\subsection{Adsorption Isotherm}

The capacity of Ag-ZVINPs to adsorb temephos was examined by measuring the initial and final concentrations of temephos in the test solution under optimum conditions in a batch system. Different water sample solutions with temephos concentration ranging from 10 to $70 \mathrm{mg} / \mathrm{L}$ were examined with fixed amount of Ag-ZVINPs (100 mg). Both Langmuir and Freundlich adsorption isotherms were used to normalize the adsorption data. The results were monitored by HPLC-UV analysis before and after removal procedure with respect to concentrations obtained from peak areas of related temephos contents in the solutions. The results showed that Langmuir model fitted better $\left(R^{2}=0.999\right)$ than the Freundlich model $\left(\mathrm{R}^{2}=0.976\right)$, demonstrating that the adsorption of temephos onto Ag-ZVINPs can be considered as a monolayer adsorption process. This may be due to the formation of a monolayer strong complex between the coated $\mathrm{Ag}$ on the surface of ZVINPs and phosphate/sulfur containingcompound (temephos) $(37,38)$ which covers the surface of Ag-ZVINPs and no more complex molecules can form on the first layer. The Langmuir isotherm equation (Equation 1) was used to describe the relationship between the amount of temephos adsorbed and its equilibrium concentration in the solutions Figure 10.

Equation 1. $\quad \frac{C}{q}=\frac{1}{\mathrm{kq}_{m}}+\frac{C}{q_{m}}$

where $\mathrm{C}(\mathrm{mg} / \mathrm{L})$ is the equilibrium concentration of the temephos in the solution, q (mg temephos per $\mathrm{g}$ adsorbent) is the equilibrium adsorption amount of temephos, $\mathrm{q}_{\mathrm{m}}$ is the maximum adsorption amount of temephos per gram of adsorbent $(\mathrm{mg} / \mathrm{g})$ and $\mathrm{K}$ is the Langmuir 
adsorption equilibrium constant in liter per mg of adsorbent (L/mg).

The linear relationship between $\mathrm{C} / \mathrm{q}$ and $\mathrm{C}(\mathrm{C} / \mathrm{q}=0.079 \mathrm{C}$ +0.241 ) shows the applicability of the Langmuir model. The experiments resulted in 0.327 for $\mathrm{K}$ (as Langmuir adsorption equilibrium constant, $\mathrm{L} / \mathrm{mg}$ ) and 12.65 for $\mathrm{q}_{\mathrm{m}}$ (as the maximum adsorption amounts of temephos per gram of adsorbent, $\mathrm{mg} / \mathrm{g}$ ), respectively.

\subsection{Effect of Electrolyte}

The effect of electrolyte concentration (adjusted by $\mathrm{KNO}_{3}$ ) on the adsorption and removal efficiency of temephos from the test solutions ( $50 \mathrm{~mL}, 10 \mathrm{mg} / \mathrm{L}$ ) was studied. The analysis was carried out under optimum conditions at room temperature. The results showed no significant effect of even high concentrations of $\mathrm{KNO}_{3}$ on the removal efficiency of temephos. This implied that the complex formation between Ag that is on the ZVINPs (Ag-ZVINPs) and temephos in the test solution was not affected significantly even by high $\mathrm{KNO}_{3}$ concentration under the examined conditions.

\subsection{Effect of Interfering Species}

The described optimum experimental conditions were used to study the effect of some ions, inorganic, and organic chemicals on the removal efficiency of temephos (25 mL, $10 \mathrm{mg} / \mathrm{L}$ ) by Ag-ZVINPs. To this end, removal of temephos was performed in the presence of co-existing ions and molecules. The maximum acceptable error was $\pm 5 \%$. The results are presented in Table 1 . According to the obtained results, some of the chemicals significantly interfered on the temephos removal efficiency. It is because of the high tendency of ZVINPs particles to remove the tested chemicals from water. For this reason, by increasing the amount of adsorbent (Ag-ZVINPs), the analyte could be removed along with most of the interfering species. By increasing the amount of adsorbent to $1.00 \mathrm{~g}$ temephos was removed up to $99 \%$ in the presence of 100 $\mathrm{mg} / \mathrm{L}$ of $\mathrm{Na}^{+}, \mathrm{K}^{+}, \mathrm{Ca}^{2+}$ and $\mathrm{NO}_{3}^{-}$.

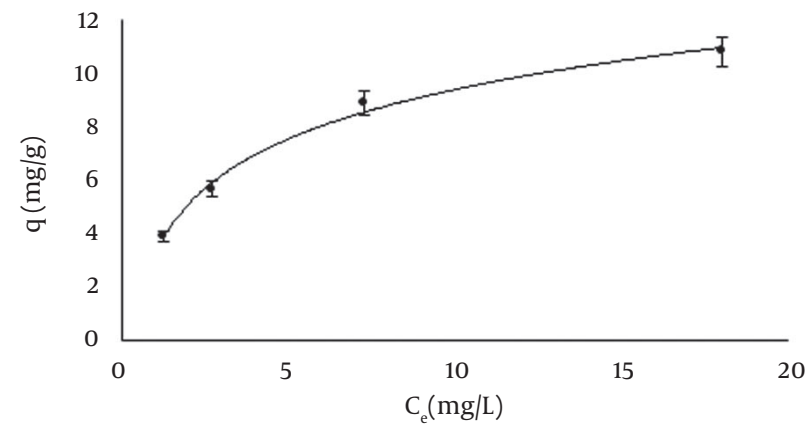

Figure 10. The Plot of $\mathrm{q}_{\mathrm{e}}(\mathrm{mg} / \mathrm{g})$ Versus $\mathrm{C}(\mathrm{mg} / \mathrm{L})$ at $25^{\circ} \mathrm{C}$ and $\mathrm{pH} 7$ with Langmuir Model Fit to the Data

\subsection{Reusability}

The ability of reusing the adsorbent in several successive adsorption processes was tested under controlled conditions (temephos $10 \mu \mathrm{g} / \mathrm{mL} ; 50 \mathrm{~mL}$ 0.05\% surfactant solution, $\mathrm{pH} 7$, contact time 30 minutes, and stirring speed $=250 \mathrm{rpm}$ ). The results showed that Ag-ZVINPs can be reused three times without a considerable loss in their adsorption efficiency (>90\%).

\subsection{Effect of Solution Volume on Temephos Remov- al Efficiency}

Different sample volumes between 12.5 and $200 \mathrm{~mL}$ were studied $(\mathrm{pH} 7$, contact time $=20$ minutes, stirring speed $=250 \mathrm{rpm}, 25^{\circ} \mathrm{C}$ ) to achieve a tolerable volume of temephos sample solution per adsorbent amount used for removal. Solution volumes were increased while the total weight of temephos in the solution remained fixed at $0.25 \mathrm{mg}$. The obtained results Figure 11 showed that the maximum removal of temephos was applicable up to 50 mL of the solutions. It must be mentioned that increasing the contact time had no significant effect on the removal efficiency even in larger volumes of temephos sample solutions, but by increasing the adsorbent amount the tolerable volume of sample solution increased.

Table 1. The Effect of Co-existing Species on the Removal Process of Temephos From Contaminated Water Samples by Ag-ZVINPs

\begin{tabular}{|c|c|}
\hline Ions & Tolerance Ratio \\
\hline $\mathbf{F}^{-}$ & 10 \\
\hline $\mathbf{H}_{2} \mathbf{O}_{2}$ & 5 \\
\hline $\mathrm{SO}_{3}{ }^{2-}, \mathrm{Ca}^{2+}$ & 0.5 \\
\hline $\mathrm{Ba}^{2+}, \mathrm{SO}_{4}{ }^{2-}, \mathrm{H}_{2} \mathrm{PO}_{4}^{-}, \mathrm{CCl}_{4}, \mathrm{CHCl}_{3}, \mathrm{NO}_{2}^{-}$ & 1 \\
\hline $\mathrm{Cu}^{2+}, \mathrm{Cr}^{6+}, \mathrm{Hg}^{2+}, \mathrm{Zn}^{2+}, \mathrm{MnO}_{4}^{-}$ & 0.1 \\
\hline $\mathrm{Pb}^{2+}, \mathrm{Cd}^{2+}, \mathrm{As}^{3+}$ & 0.05 \\
\hline
\end{tabular}

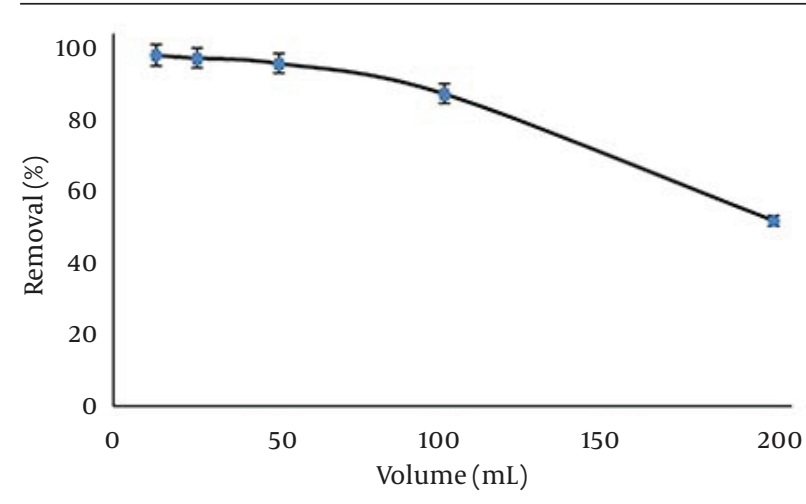

Figure 11. Effect of Sample Volume Tolerance Limit on the Quantitative Removal of $250 \mu \mathrm{g}$ of Temephos. Conditions: $\mathrm{pH} 7$; contact time 10 minutes; $100 \mathrm{mg}$ Ag-ZVINPs 
Table 2. Removal of Temephos (Spiked) From Different Water Samples Using Ag-ZVINPs

\begin{tabular}{lc}
\hline $\begin{array}{l}\text { Water Samples, Spiked Temephos Concen- } \\
\text { tration, mg/L }\end{array}$ & Removal, \% \\
\hline Ahvaz (Khuzestan, Iran) drinking water & - \\
\hline 0 & 98.1 \\
\hline 5 & 98.5 \\
\hline 10 & \\
\hline $\begin{array}{l}\text { The water from Karoon River passing } \\
\text { through Khoramshahr City (Khuzestan, }\end{array}$ \\
Iran) \\
\hline 0 & \\
\hline 5 & - \\
\hline 10 & 98.0 \\
\hline The Caspian Sea (Iran) & 97.5 \\
\hline 0 & \\
\hline 5 & - \\
\hline 10 & 97.0 \\
\hline
\end{tabular}

\subsection{Real Samples}

To verify the applicability and reliability of the proposed designated method for temephos removal, three different samples, as described in the previous sampling section, were collected. Temephos was spiked to the water samples in such a way that the final concentrations of temephos were fixed at $10 \mathrm{mg} / \mathrm{L}$. No matrix modification was done before and after the removal process. All the analyses were carried out under optimized conditions. The analyte concentrations before and after removal process were determined by HPLC-UV system. The results given in Table 2 proved the capability of the method to remove temephos from real samples with no matrix modification.

\section{Discussion}

A fast, simple and effective magnetic solid phase removal of temephos insecticide from aqueous solutions was successfully developed with Ag-ZVINPs as an adsorbent. Such a removal process by magnetic nanoparticles was carried out for the first time. The adsorbent could be manipulated magnetically and exhibited high adsorption capacity and fast adsorption rates to remove temephos due to binding to $\mathrm{Ag}(37,38)$ of Ag-ZVINPs, high specific surface area and absence of internal diffusion resistance. The adsorption behavior could be described by Langmuir isotherm. The adsorbent may also be useful to remove other substances such as heavy metal ions from aqueous solutions. The whole removal (adsorption) processes can be completed within 10 minutes. The proposed method showed high potential for fast removal of temephos from surface water samples with high efficiency.

\section{Acknowledgements}

The authors wish to thank Shahid Chamran University Research Council and Food and Drug Safety Evaluation Research Center of Jundishapur University of Medical Sciences for their financial supports.

\section{Authors' Contributions}

Study design and supervision: Dr. Hooshang Parham; data collection and manuscript preparation: Dr. Roohollah Shiralipour ; Statistical analysis and data interpretation: Dr. Behrooz Zargar; Critical revision of the manuscript: Dr. Hooshang Parham and Dr. Behrooz Zargar.

\section{Funding/Support}

Shahid Chamran University and Food and Drug Safety Evaluation Research Center of Jundishapur University of Medical Sciences, Ahvaz, Iran, financially supported this study.

\section{References}

1. Williams PL, James RC, Roberts SM. Principles of Toxicology: Environmental and Industrial Applications.: Wiley; 2003.

2. Jeyaratnam J, Maroni M. Organophosphorous compounds. Toxicology. 1994;91(1):15-27.

3. WHO.. Temephos in Drinking-water: Use for Vector Control in Drinking-water Sources and Containers, Background document for development of WHO Guidelines for Drinking-water Quality:: World Health Organization; 2009.

4. Lee C, Kim JY, Lee WI, Nelson KL, Yoon J, Sedlak DL. Bactericidal effect of zero-valent iron nanoparticles on Escherichia coli. Environ Sci Technol. 2008;42(13):4927-33.

5. Diao M, Yao M. Use of zero-valent iron nanoparticles in inactivating microbes. Water Res. 2009;43(20):5243-51.

6. Lin YT, Weng CH, Chen FY. Effective removal of AB24 dye by nano/ micro-size zero-valent iron. Sep PurifTechnol. 2008;64(1):26-30.

7. Fan J, Guo Y, Wang J, Fan M. Rapid decolorization of azo dye methyl orange in aqueous solution by nanoscale zerovalent iron particles. J Hazard Mater. 2009;166(2-3):904-10.

8. Shu HY, Chang MC, Chen CC, Chen PE. Using resin supported nano zero-valent iron particles for decoloration of Acid Blue 113 azo dye solution.J Hazard Mater. 2010;184(1-3):499-505.

9. Chatterjee S, Lim SR, Woo SH. Removal of Reactive Black 5 by zero-valent iron modified with various surfactants. Chem Eng J. 2010;160(1):27-32.

10. Frost RL, Xi Y, He H. Synthesis, characterization of palygorskite supported zero-valent iron and its application for methylene blue adsorption. J Colloid Interface Sci. 2010;341(1):153-61.

11. Shahwan T, Abu Sirriah S, Nairat M, Boyacı E, Eroğlu AE, Scott TB, et al. Green synthesis of iron nanoparticles and their application as a Fenton-like catalyst for the degradation of aqueous cationic and anionic dyes. Chem Eng J. 2011;172(1):258-66.

12. Chen ZX, Jin XY, Chen Z, Megharaj M, Naidu R. Removal of methyl orange from aqueous solution using bentonite-supported nanoscale zero-valent iron. J Colloid Interface Sci. 2011;363(2):601-7.

13. Rangsivek R, Jekel MR. Removal of dissolved metals by zero-valent iron (ZVI): kinetics, equilibria, processes and implications for stormwater runoff treatment. Water Res. 2005;39(17):4153-63.

14. Uzum C, Shahwan T, Eroglu, A.E. , Lieberwirth, I. , Scott, T. B., Hallam, K. R. . Application of zero-valent iron nanoparticles for the removal of aqueous $\mathrm{Co}+$ ions under various experimental conditions. Chem EngJ . 2008;144(2):213-20.

15. Efecan N, Shahwan T, Eroğlu AE, Lieberwirth I. Characterization of the uptake of aqueous Ni2+ ions on nanoparticles of zerovalent iron (nZVI). Desalination. 2009;249(3):1048-54.

16. Mak MS, Rao P, Lo IM. Effects of hardness and alkalinity on 
the removal of arsenic(V) from humic acid-deficient and humic acid-rich groundwater by zero-valent iron. Water Res. 2009;43(17):4296-304.

17. Liu T, Zhao L, Sun D, Tan X. Entrapment of nanoscale zero-valent iron in chitosan beads for hexavalent chromium removal from wastewater. J Hazard Mater. 2010;184(1-3):724-30.

18. Zhang Y, Li Y, Zheng X. Removal of atrazine by nanoscale zero valent iron supported on organobentonite. Sci Total Environ. 2011;409(3):625-30.

19. Singhal RK, Gangadhar B, Basu H, Manisha V, Naidu GRK, Reddy AVR. Remediation of Malathion Contaminated Soil Using Zero Valent Iron Nano-Particles. American J Anal Chem. 2012;3(1):76-82.

20. Ponder SM, Darab JG, Mallouk TE. Remediation of $\mathrm{Cr}(\mathrm{VI})$ and $\mathrm{Pb}(\mathrm{II})$ Aqueous Solutions Using Supported, Nanoscale Zero-valent Iron. Environ Sci Technol. 2000;34(12):2564-9.

21. Feng J, Lim TT. Iron-mediated reduction rates and pathways of halogenated methanes with nanoscale Pd/Fe: analysis of linear free energy relationship. Chemosphere. 2007;66(9):1765-74

22. Geng B, Jin Z, Li T, Qi X. Preparation of chitosan-stabilized Fe(0) nanoparticles for removal of hexavalent chromium in water. $\mathrm{Sci}$ Total Environ. 2009;407(18):4994-5000.

23. Cho Y, Choi SI. Degradation of PCE, TCE and 1,1,1-TCA by nanosized FePd bimetallic particles under various experimental conditions. Chemosphere. 2010;81(7):940-5.

24. Chen H, Luo H, Lan Y, Dong T, Hu B, Wang Y. Removal of tetracycline from aqueous solutions using polyvinylpyrrolidone (PVP-K30) modified nanoscale zero valent iron. J Hazard Mater. 2011;192(1):44-53.

25. Yoshizuka K, Lou Z, Inoue K. Silver-complexed chitosan microparticles for pesticide removal. React Funct Polym. 2000;44(1):47-54.

26. Sumesh E, Bootharaju MS, Pradeep T, Anshup , . A practical silver nanoparticle-based adsorbent for the removal of $\mathrm{Hg} 2+$ from water. J Hazard Mater. 2011;189(1-2):450-7.

27. Shahverdi AR, Fakhimi A, Shahverdi HR, Minaian S. Synthesis and effect of silver nanoparticles on the antibacterial activity of different antibiotics against Staphylococcus aureus and Escherichia coli. Nanomedicine. 2007;3(2):168-71.

28. Espinosa-Cristobal LF, Martinez-Castanon GA, Martinez-Martinez
RE, Loyola-Rodriguez JP, Patino-Marin N, Reyes-Macias JF, et al. Antibacterial effect of silver nanoparticles against Streptococcus mutans. Mater Lett. 2009;63(29):2603-6.

29. Wei D, Sun W, Qian W, Ye Y, Ma X. The synthesis of chitosan-based silver nanoparticles and their antibacterial activity. Carbohydr Res. 2009;344(17):2375-82.

30. Pallavicini P, Taglietti A, Dacarro G, Diaz-Fernandez YA, Galli M Grisoli P, et al. Self-assembled monolayers of silver nanoparticles firmly grafted on glass surfaces: low $\mathrm{Ag}+$ release for an efficient antibacterial activity. J Colloid Interface Sci. 2010;350(1):110-6.

31. Ravindra S, Murali Mohan Y, Narayana Reddy N, Mohana Raju K. Fabrication of antibacterial cotton fibres loaded with silver nanoparticles via "Green Approach". Colloids Surf A Physicochem Eng Asp. 2010;367(1-3):31-40.

32. Zhao L, Wang H, Huo K, Cui L, Zhang W, Ni H, et al. Antibacterial nano-structured titania coating incorporated with silver nanoparticles. Biomaterials. 2011;32(24):5706-16.

33. Quang DV, Sarawade PB, Hilonga A, Kim JK, Chai YG, Kim SH, et al. Preparation of amino functionalized silica micro beads by dry method for supporting silver nanoparticles with antibacterial properties. Colloids Surf A Physicochem Eng Asp. 2011;389(1-3):118-26.

34. Hebeish A, El-Naggar ME, Fouda MMG, Ramadan MA, Al-Deyab SS, El-Rafie MH. Highly effective antibacterial textiles containing green synthesized silver nanoparticles. Carbohydr Polym. 2011;86(2):936-40.

35. Guzman M, Dille J, Godet S. Synthesis and antibacterial activity of silver nanoparticles against gram-positive and gram-negative bacteria. Nanomedicine. 2012;8(1):37-45.

36. Xue CH, Chen J, Yin W, Jia ST, Ma JZ. Superhydrophobic conduc tive textiles with antibacterial property by coating fibers with silver nanoparticles. Appl SurfSci. 2012;258(7):2468-72.

37. Ladhe AR, Frailie P, Hua D, Darsillo M, Bhattacharyya D. Thiol Functionalized Silica-Mixed Matrix Membranes for Silver Capture from Aqueous Solutions: Experimental Results and Modeling. J Memb Sci. 2009;326(2):460-71.

38. Tripathy SK, Yu YT. Spectroscopic investigation of S-Ag interaction in omega-mercaptoundecanoic acid capped silver nanoparticles. Spectrochim Acta A Mol Biomol Spectrosc. 2009;72(4):841-4. 